\title{
Position-optimization on retained entry and backfilling wall in gob-side entry retaining techniques
}

\author{
Xiaowei Feng ${ }^{1} \cdot$ Nong Zhang ${ }^{1,2}$
}

Received: 10 March 2015/Revised: 2 June 2015 / Accepted: 5 June 2015/Published online: 11 August 2015

(C) The Author(s) 2015. This article is published with open access at Springerlink.com

\begin{abstract}
This study investigates the stability problem of gob-side entry retaining (GER) and backfilling wall which located under the key block B. Based on the combined research of elastic-plastic mechanics, structure mechanics and modern theory of mining-induced pressure, the caving characteristic and roof structure over the GER were analyzed, and the vertical force and the torque on retained entry roof were also derived as the position for the retained entry varies. On the basis of the specific geology in Huainan mining area, the results indicate that a relatively more stable position for retained entry neighbors the hinge point of block $\mathrm{A}$ and $\mathrm{B}$, and it also located at a scope ranging from this point to the one-third length of block B in horizontal direction. As to appropriate position for backfilling wall, this study recommends partialroad-in backfilling method for GER. Field trial conducted at panel face 12418 of Xieqiao Mine demonstrates that the recommended width for original entry is $3.6 \mathrm{~m}$ and the preferred width proportion between original retained entry and original entry is $75 \%$ or so whereas the avoidable one is $88 \%$ or so. These findings provide qualitative references to the mines which share similar geology as what Huainan mining area characterized.
\end{abstract}

Keywords Mining engineering · Position-optimization · Gob-side entry retaining · Partial-road-in backfilling

\section{Introduction}

Generally, gob-side entry retaining (GER), which reserves the headgate of previous district sublevel and turn it into the tailgate of next district sublevel, is a promising green mining method, and also has great economic benefits (Xu 2009; Xue et al. 2013; Zhang et al. 2014). Nonetheless, it is the backfilling wall that plays a major role in this engineering method, and the main function of backfilling wall in GER is to hold up potential strata separation of

Xiaowei Feng

fxw_mining@foxmail.com

1 Key Laboratory of Deep Coal Resource Mining (Ministry of Education of China), School of Mines, China University of Mining and Technology, Xuzhou 221116, China

2 Hunan Key Laboratory of Safe Mining Techniques of Coal Mines, Hunan University of Science and Technology, Xiangtan 411201, China immediate roof and main roof, and it is also capable of cutting off lateral main roof in an appropriate moment to avoid overlarge pressure or torque. Thus the caving gangue in gob area can support the main roof, and it also can reduce the bending/subsidence of overlying strata and load on the supports in retained entry. At the same time, the backfilling wall can isolate gob area and entry space, it prevents potential leakage of harmful gases sourced from gob side. Hence it requires higher working resistance, larger resistance-increasing velocity, and enough yield ability on related supports in retained entry (Qian et al. 2010). The kernel to the success of GER is whether the entry-side supports can adapt to the movement law of roof and efficiently control the roof strata or not (Li 2000; Yang et al. 2013; Zhang et al. 2013).

Many reports documented profound results concerning the technical problems of GER. Zhang et al. (2005) suggested original-position GER in view of the roof movement law of the fully-mechanized coalface with top-coal caving, whose main technical scheme was to take large section 
digging and directly construct backfilling strip along the gob-side entry, therefore the whole backfilling strip can be protected by the origin support forms in the entry (Ma and Zhang 2004). Kan et al. (2011) held their opinion that support resistance on the backfilling wall can be reduced by improving the roof bearing capability around the backfilling area. Huang et al. (2011) aimed at the technical difficulties of GER in fully-mechanized coalface with solid material backfilling and they also analyzed structural mechanics model of surrounding rock, then they put forward a new technical for entry side backfilling. A Scholar named Williams (1988) of the former Soviet Union proposed a suspension girder model under the stope pressure, and he then got the equations for the working resistance of road-side support needed to cut off the immediate roof based on his study on GER. British scholar Smart and Davies (1982) proposed a Roof Beam Tilt Theory, and its basic idea was to restrict the roof subsidence in entry from the coal side to the edge of gob side, he also put forward the standpoints that the inclination angle of roof and the rotation fulcrum position should act as two important parameters as to support design for retained entry.

On the basis of the aforementioned results, the vertical force and torque on the gob-side entry were obtained as the position of the entry varies under the key block B, then the method of partial-road-in backfilling for GER was presented and applied to the Xieqiao Mine.

\section{Spacial forms of lateral structure's key block B}

\subsection{Fractured mechanism of overlying strata on gob-side entry}

Overlying strata on coal mass will gradually bend down due to coal excavation under it, the strata can finally break off when the hanging distance reaches its extremity, then some blocks with different sizes or different spatial orientation will come into forming. The lateral key block B is generally formed by the caving of overlying strata, which shows an obvious difference with those blocks along the advancing direction of coal mining face. The fractured direction of block B is simultaneously perpendicular to the advancing direction of panel face and the central axis of entry. On the whole, the fractured spacial form is illustrated in Fig. 1. It can be observed from Fig. 1 that the fracture of overlying strata happened twice, one in coal extraction of previous district sublevel while the other is in current district sublevel, both of them can apply great stress disturbance on the roof of gob-side retained gateroad (entry). Hence, it is very important to seek the best location of entry so as to sustain the stability of it and keep it away from the frequent influence of high stress. As been long testified by

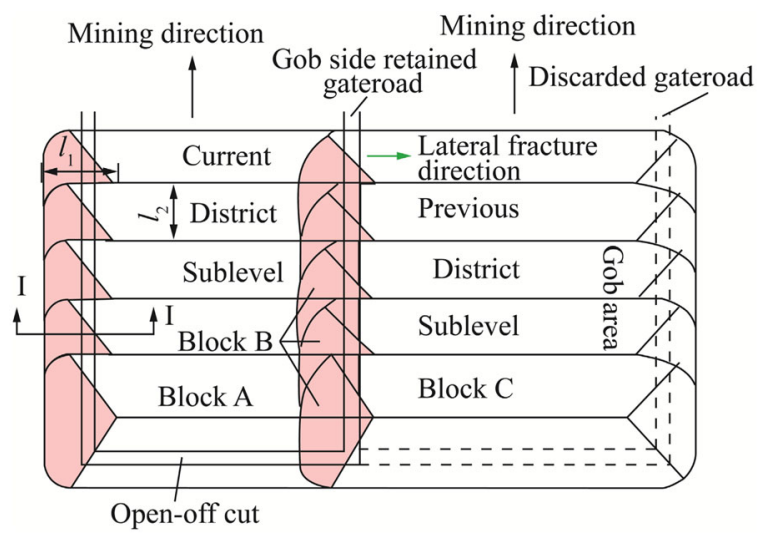

Fig. 1 Plane relation of gob-side retained entry and overlying fractured strata

existing documents, the key block B should shape like an arc triangular section after the lateral strata fractured (Zhu 1987), then the entry stress environment of different positions under block B is investigated in this paper.

I-I section in Fig. 1 is explicitly illustrated in Fig. 2a, which shows the state when the lateral strata is totally fractured. In order to analyze the break mechanism of the roof thoroughly, an experiment named similar material simulation was carried out to interact with actual field situation, which simulates the fractured form of roof in GER to some extend. As the panel face moves forward, the

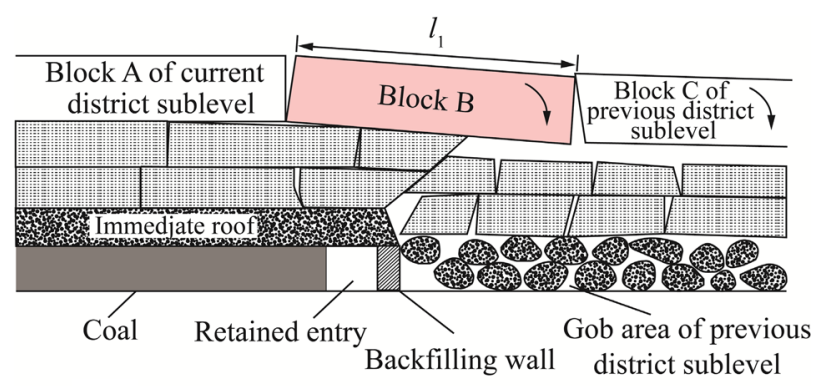

(a) Arc triangular section of overlying strata in GER (Section I-I in Fig. 1)

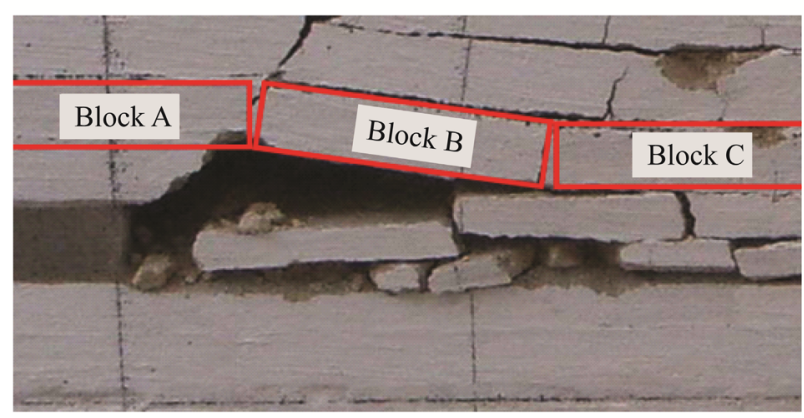

(b) Fractured blocks A, B and C in similar material

Fig. 2 Comparison between theoretical model and similar material simulation experiment 
lateral overlying strata at the rear part of the mining face will bend firstly and then break off, finally, a situation photographed in Fig. $2 \mathrm{~b}$ can be formed. By comparing these two figures, it is generally accepted that the fractured model shown in Fig. 2a is quite reasonable under certain roof conditions and approximate conditions. Because of the roof bending and strata subsidence, a hinged structure can be created by blocks $\mathrm{A}, \mathrm{B}$, and $\mathrm{C}$ together, and it is obviously that these blocks have different levels of influence on the stress distribution of surrounding rock around the retained entry. Now consider the lateral form in Fig. 2a, block $\mathrm{C}$ is mostly supported by caving gangue in the gob area, whereas most part of block $A$ is supported by the underlying coal mass. It is certainly that block A have a significant influence on the stress distribution of coal mass. The exact reason of importance of block B lies in the fact that its left-handed end lies on the strata whereas the righthanded end is hinged to the left corner of Block C. Hence, the stability of entry is greatly depended on the special position of block $\mathrm{B}$, and its related optimized position analysis is of vital significance.

\subsection{Stress environment of different entry positions under key block B}

There are several main parameters that can influence the stress environment of different entry positions under key block $\mathrm{B}$, i.e. the fractured length $l_{2}$ along the advancing direction of coal excavation, lateral fractured length $l_{1}$ which is perpendicular to the advancing direction, and the thickness $h$ of the key block B, labeled as in Fig. 1 .

\subsubsection{Forces analysis of different entry positions (impacts of block $B$ )}

(1) Solution of $l_{1}$ in Fig. 1

$l_{1}$ is the length of the lateral fractured structure as overlying strata breaks off, it is closely related to the length $(s)$ of panel face and the periodic weighting distance $l_{2}$, their relationship can be expressed as below (Jiang 1993):

$l_{1}=\frac{2 l_{2}}{17}\left[\sqrt{\left(10 \frac{l_{2}}{s}\right)^{2}+102}-10 \frac{l_{2}}{s}\right]$

(2) Solution of $l_{2}$ in Fig. 1

$l_{2}$ is the periodic weighting distance along the advancing direction of panel face, and its specific value can be measured by field observation, the empirical equation for $l_{2}$ is expressed in Eq. (2) (Chen and Qian 1994),

$$
l_{2}=h \sqrt{\frac{R_{t}}{3 q}}
$$

where $h$ is the thickness of block $\mathrm{B}$, in meters, $R_{t}$ is the tensile strength of immediate roof, in $\mathrm{MPa}$, and $q$ is the stress on unit area of immediate roof, in MN/ $\mathrm{m}^{2}$.

According to research conducted by Jiang (1993), $l_{1}$ is approximately equals to $l_{2}$ under the circumstance that the ratio between $s$ and $l_{2}$ is larger than 6 . In view of the practical situation that the periodic weighting distance in most of mines is $10-20 \mathrm{~m}$ or so whereas the general length of panel face is $120-250 \mathrm{~m}$ or so. Then it is obviously that the ratio surpasses 6 . Hence, the lateral length equals to the periodic weighting distance of immediate roof in long wall mining activities, namely, $l_{1}=l_{2}$.

In actual practices, the retained entry can have several potential positions, and these positions can distribute under block A or block B. Accordingly, it should have four corresponding positions, they are labeled by $P_{\mathrm{I}}, P_{\mathrm{II}}, P_{\mathrm{III}}$, and $P_{0}$, as indicated in Fig. 3. The retained entry can be relatively stable when its position is $\mathrm{P}_{0}$, where the stress environment belongs to a relatively relaxed area, this area can range up to $7 \mathrm{~m}$ from the edge of coal side (Bai et al. 2000). However, this stable situation can be altered if the position is located at $\mathrm{P}_{\mathrm{I}}, \mathrm{P}_{\mathrm{II}}$ or $\mathrm{P}_{\mathrm{III}}$, where the fracture, rotation, and the overwhelming subsidence can apply huge complicated stress on the retained entry (Xie 2004; Zhang et al. 2002). Hence, block B plays a major role as to surrounding rock support of retained entry. In order to figure out the optimal position, here block $B$ is divided into three parts, each part is a third length of rock $B$, as illustrated by $l_{1} / 3,2 l_{1} / 3$, and $l_{1}$ in Fig. 3 .

On account of the fact that the rotation angle $(\theta)$ of block $\mathrm{B}$ is relatively small whereas its length $\left(l_{1}\right)$ is relatively large, then a hypothesis is set as: the stress direction of overlying strata is perpendicular to the face of rock B, the horizontal stress should be ignored because of its slight impact on overall stability of the hinged structure. Figure 3

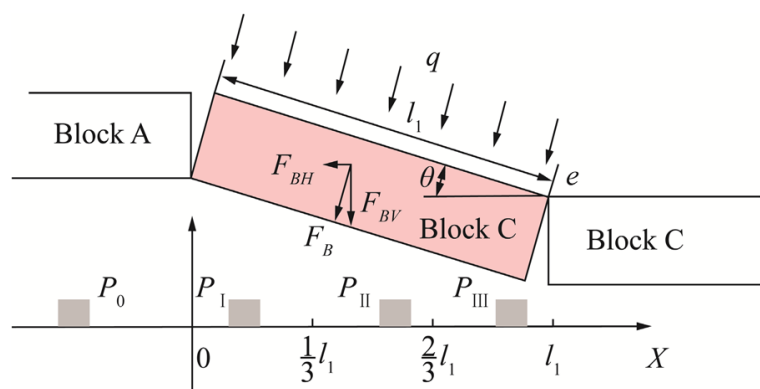

Fig. 3 Different positions of retained entry under block A and B 
presents these hypothesis, where $q$ represents uniform force.

Block B and block $\mathrm{C}$ are hinged together with each other at point $e$, which makes the area around this point shows a plastic trend, the horizontal extrusion force and the vertical shear force concentrate on this point. Nonetheless, these forces should be neglected because the stability of entry, no matter in $P_{\mathrm{I}}, P_{\mathrm{II}}$ or $P_{\mathrm{III}}$, is much more sensitive to the vertical factors induced by block B and overlying strata on block B.

Based on aforementioned hypothesis, block B and certain part of block $\mathrm{C}$ are isolated and shaped like isosceles triangle. The plan view in rectangular coordinate system is shown in Fig. 4.

In view of Fig. 4, linear equation for the side of triangle in the first quadrant should be expressed as

$\frac{x}{l_{1}}+\frac{y}{l_{2}}=1$

As to higher coal side, its $\mathrm{x}$-coordinate is $x_{0}$ and the corresponding $\mathrm{y}$-coordinate is:

$y_{1}=\left(1-\frac{x_{0}}{l_{1}}\right) l_{2}$

When the entry is located at $P_{\mathrm{I}}$, the $x$-coordinate of the lower backfilling wall side is $x_{0}+a$ and corresponding ycoordinate is:

$y_{2}=\left(1-\frac{x_{0}+a}{l_{1}}\right) l_{2}$

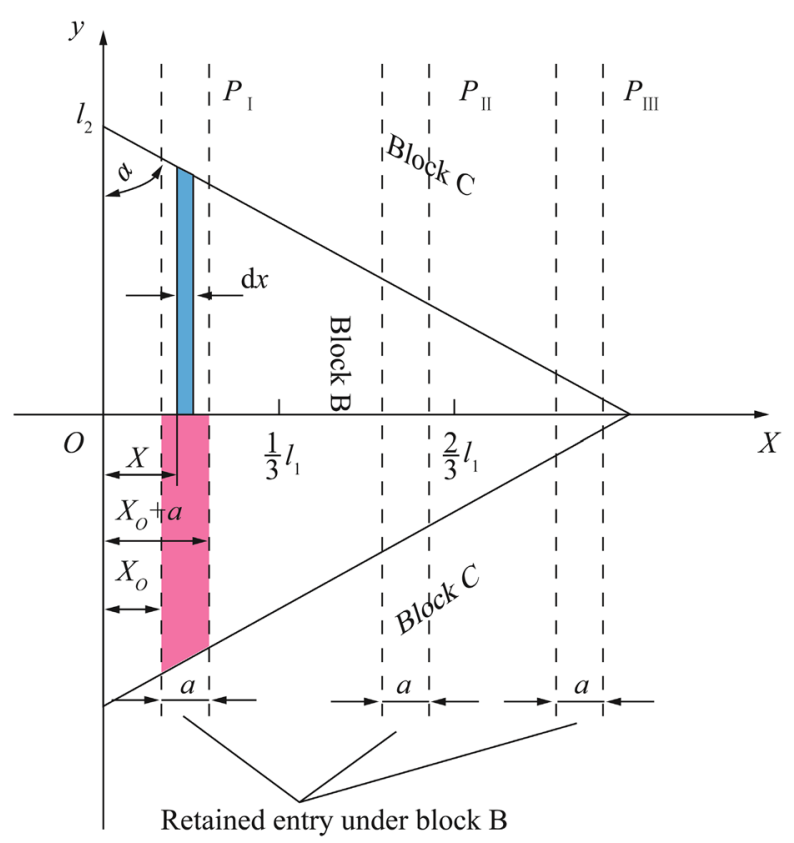

Fig. 4 Structure analysis of isolated key block B and certain part of block $\mathrm{C}$ in GER
Hence, the red shaded area in Fig. 4 should be expressed as,

$S_{0}=\frac{1}{2}\left(y_{1}+y_{2}\right) a$

Combine equations from (3) to (6), then,

$S_{0}=\frac{1}{2}\left(2-\frac{2 x_{0}+a}{l_{1}}\right) l_{2} a$

As to position $P_{\mathrm{I}}$, the total overlying area above the entry is $2 S_{0}$. Then the force applied on the entry can be obtained by taking the uniform load $q$ into consideration, the direction of the force is perpendicular to the upper surface of block B and it simultaneously slants down, as labeled by $F_{\mathrm{B}}$ in Fig. 3. This force can be decomposed into horizontal force $F_{B H}$ and vertical force $F_{B V}, F_{B H}$ should be ignored for its small value. In addition, the dead weight of rock $B$ also should be added, whose direction is straight down to the floor of coal seam. On the basis of above analysis, the resultant vertical force on the roof of the retained entry is expressed as below

$F_{B V}=l_{2} a\left(2-\frac{2 x_{0}+a}{l_{1}}\right)(q \cos \theta+\gamma h)$

where $\gamma$ is the bulk density of rock, in $\mathrm{MN} / \mathrm{m}^{3}, h$ is the thickness of rock $\mathrm{B}$, in meters, $a$ is the width of entry, in meters, and $\theta$ is the rotating angle of rock $\mathrm{B}$, in degrees.

\subsubsection{Forces analysis of different entry positions (impacts of overlying coal mass under block B)}

Coal mass under block B also can influence stress distribution around the surrounding rock of entry, different positions of the entry under block B will induce different stress environment around the entry. Here in this section the stress concerned with the coal mass under block B is considered.

As shown in Fig. 4, the blue shaded area can be calculated by integral method, and the vertical stress of coal mass under the arc triangular block $\mathrm{B}$ is expressed in Eq. (9) (Hou and Ma 1989; Bai et al. 2004),

$\sigma_{y}=\left(\frac{C_{0}}{\tan \varphi_{0}}+\frac{P_{z}}{A}\right) \mathrm{e}^{\frac{2 \tan \varphi_{0}}{M A} x}-\frac{C_{0}}{\tan \varphi_{0}}$

where $M$ is the mining height, in meters, $A$ is the side pressure coefficient, $\varphi_{0}$ is the internal friction angle of coal mass, in degrees, $C_{0}$ is the cohesion of coal mass, in MPa, $K$ is the stress concentration factor, $H$ is the burial depth of entry, $\gamma$ is bulk density of overlying strata, in $\mathrm{MN} / \mathrm{m}^{3}$, and $P_{\mathrm{z}}$ is the support resistance of coal side, in MPa.

(1) Pressure solution of coal mass

In view of integral method, pressure on the entry induced by coal mass is expressed as below, 
$F_{\mathrm{m}}=\int_{x_{0}}^{x_{0}+a} \sigma_{y}\left(2 \frac{l_{1}-x}{\tan \alpha}\right) \mathrm{d} x$

Based on Eqs. (9)-(10), a combined transformation form is

$$
\begin{aligned}
F_{\mathrm{m}}= & \frac{2}{\tan \alpha}\left\{\frac{A_{1}}{A_{2}} \mathrm{e}^{A_{2}\left(X_{0}-x_{0}\right)}\right. \\
& \times\left[a \mathrm{e}^{-A_{2} a}+\left(x_{0}+\frac{1}{A_{2}}-l_{1}\right)\left(\mathrm{e}^{-A_{2} a}-1\right)\right] \\
& \left.+A_{3} a\left(\frac{a}{2}+x_{0}-l_{1}\right)\right\}
\end{aligned}
$$

(2) Torque solution of coal mass

Similarly, the torque of coal mass also should be considered, the equation for it is shown as below,

$R_{m}=\int_{x_{0}}^{x_{0}+a} \sigma_{y}\left(2 \frac{l_{1}-x}{\tan \alpha}\right) x \mathrm{~d} x$

Then a combined transformation form also can be obtained in the same measure, as shown in Eq. (13),

$$
\begin{aligned}
R_{m}= & \frac{2 A_{1}}{A_{2} \tan \alpha} e^{A_{2} x_{0}}\left\{\left[\left(x_{0}+a\right)\left(l_{1}-x_{0}-a+\frac{2}{A_{2}}\right)\right.\right. \\
& \left.\left.-\frac{l_{1}}{A_{2}}-\frac{2}{A_{2}^{2}}\right] \mathrm{e}^{A_{2} a}+\left(x_{0}^{2}-l_{1} x_{0}+\frac{2}{A_{2}^{2}}+\frac{l_{1}}{A_{2}}-\frac{2 x_{0}}{A_{2}}\right)\right\} \\
& +\frac{A_{3}}{\tan \alpha}\left[2 a x_{0}^{2}+2\left(a-l_{1}\right) a x_{0}+a^{2}\left(\frac{2 a}{3}-l_{1}\right)\right]
\end{aligned}
$$

Some variables in Eqs. (11) and (13) are listed as below,

$A_{1}=\frac{C_{0}}{\tan \varphi_{0}}+\frac{p_{z}}{A}, \quad A_{2}=\frac{2 \tan \varphi_{0}}{M A}, \quad A_{3}=\frac{C_{0}}{\tan \varphi_{0}}$

By combining analysis in Sect. 2.2.1 and 2.2.2 together, and considering the comprehensive mechanical function of key block B and coal mass together, the total vertical force on the roof of the entry is expressed as below

$$
\begin{aligned}
F_{V}= & F_{m}+F_{B V}=\frac{2}{\tan \alpha}\left\{\frac { A _ { 1 } } { A _ { 2 } } \mathrm { e } ^ { A _ { 2 } x _ { 0 } } \left[-a e^{A_{2} a}\right.\right. \\
& \left.\left.+\left(A_{4}-1\right) \frac{\left(1-\mathrm{e}^{A_{2} a}\right)}{A_{2}}\right]+\frac{A_{3} a}{2}\left(A_{4}+a\right)\right\} \\
& -\frac{l_{2} a}{l_{1}}\left(A_{4}+a_{1}\right)(q \cos \theta+\gamma h)
\end{aligned}
$$

where $A_{4}$ represents $2\left(x_{0}-l_{1}\right)$. And the torque on different entry positions is

$$
\begin{aligned}
R_{m}= & \frac{2 A_{1}}{A_{2} \tan \alpha} e^{A_{2} x_{0}}\left\{\left[\left(x_{0}+a\right)\left(l_{1}-x_{0}-a+\frac{2}{A_{2}}\right)\right.\right. \\
& \left.\left.-\frac{l_{1}}{A_{2}}-\frac{2}{A_{2}^{2}}\right] \mathrm{e}^{A_{2} a}+\left(x_{0}^{2}-l_{1} x_{0}+\frac{2}{A_{2}^{2}}+\frac{l_{1}}{A_{2}}-\frac{2 x_{0}}{A_{2}}\right)\right\} \\
& +\frac{A_{3}}{\tan \alpha}\left[2 a x_{0}^{2}+2\left(a-l_{1}\right) a x_{0}+a^{2}\left(\frac{2 a}{3}-l_{1}\right)\right]
\end{aligned}
$$

where $x_{0}$ is the horizontal length from the higher coal side of entry to the hinge point of rock $\mathrm{A}$ and $\mathrm{B}$, and $a$ is the width of entry.

In order to testify the above theoretical results, it is necessary to adapt the results into appropriate field trials. Here the strata mechanical parameters of Xieqiao Mine were analyzed and shown in Table 1. By incorporating Table 1 and Eqs. (14)-(15) together, and notice that $l_{1}=l_{2}$, the relationship among $F_{\mathrm{V}}\left(R_{\mathrm{m}}\right), a$ and $x_{0}$ can be obtained with the assistance of software MATLAB, the results are presented in Fig. 5.

Figure 5 indicates that different entry positions can lead to different stress distribution on the roof. Forces on the roof are greatly correlated to corresponding overlying area on the roof, and the area equals to the double area of the red shaded part in Fig. 4. $R_{\mathrm{m}}$ remains its exponential increase throughout the increase of $x_{0}$ whereas $F_{\mathrm{V}}$ will increase firstly and then it shows a decrease trend. The peak value of $F_{\mathrm{V}}$ is $5.87 \times 10^{3} \mathrm{MN}$, which is attained as $x_{0}$ reaches to $17 \mathrm{~m}$. It is deserved to be mentioned that $R_{\mathrm{m}}$ plays a dominant role as to the overall stability of entry because of its dramatic action value on the roof. Hence, $R_{\mathrm{m}}$ is one of the main factors depending on the appropriate positions of the entry, and this verdict can still works even $F_{\mathrm{V}}$ is showing its decreasing trend when $x_{0}$ surpasses $17 \mathrm{~m}$.

Above analysis leads to a conclusion that $P_{\mathrm{I}}$ is the optical one among three preliminary set positions under block $B$. This position neighbors the hinge point of block $A$ and $\mathrm{B}$, and it is also located at a scope ranging from this point to the one-third length of block $B$, in this scope, the stress distribution around the roof is much more mitigated and the correlated surrounding rock support is also technically feasible and economic.

\subsection{Position optimization on backfilling wall}

There are, under the existing methods, four types of potential positions for the backfilling wall in GER, which is total-gob-in backfilling, partial-road-in backfilling, totalroad-in backfilling and next-to-coal backfilling. The totalroad-in backfilling is overall positioned in the retained entry, it thus can utilize the original supports in the entry, such as bolts, cables, or props (Zheng et al. 2014), the outer 
Table 1 Mechanical parameters of coal and strata in Xieqiao Mine

\begin{tabular}{|c|c|c|c|c|c|c|}
\hline$C_{0}(\mathrm{Mpa})$ & $\varphi_{0}\left({ }^{\circ}\right)$ & $P_{z}(\mathrm{Mpa})$ & $Q\left(\mathrm{MN} / \mathrm{m}^{2}\right)$ & $A$ & $M(\mathrm{~m})$ & $\Theta\left({ }^{\circ}\right)$ \\
\hline 0.80 & 30 & 0.30 & 15.38 & 1.4 & 2.80 & 19 \\
\hline$K$ & $\Gamma\left(\mathrm{MN} / \mathrm{m}^{3}\right)$ & $H(\mathrm{~m})$ & $l_{1}\left(l_{2}\right)(\mathrm{m})$ & $H(\mathrm{~m})$ & $X_{0}(\mathrm{~m})$ & $A\left({ }^{\circ}\right)$ \\
\hline 1.50 & 0.03 & 615 & 22 & 5.18 & 9.24 & 63.4 \\
\hline
\end{tabular}

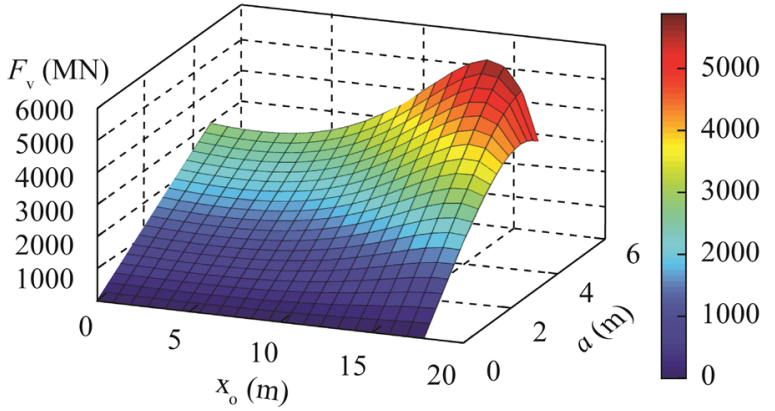

(a)

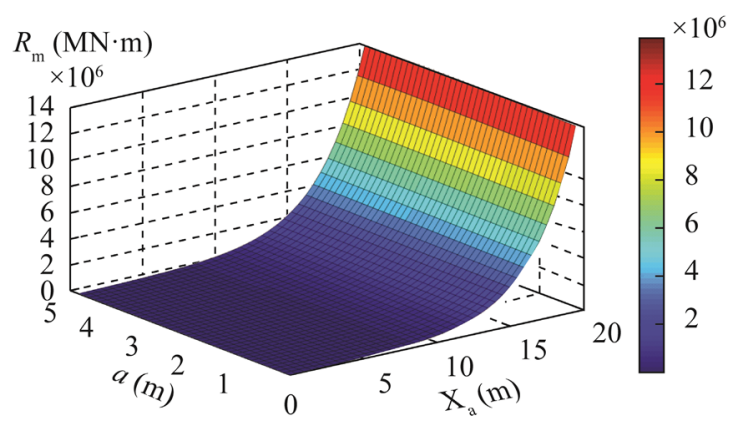

(b)

Fig. 5 Overall relationship among $F_{\mathrm{V}}\left(R_{\mathrm{m}}\right), x_{0}$, and $a$

flank of this kind of backfilling wall faces to the gob area, as indicated in Fig. 6c. The total-gob-in backfilling is in opposite form of the total-road-in backfilling, which is overall positioned in the gob area, its inner flank faces to the coal side and its stability cannot be extra reinforced by the original supports in the entry, as indicated in Fig. 6a. The partial-road-in backfilling is a combined form of above two backfilling methods, which means the partial width of backfilling wall lies in entry side whereas the rest part is in gob side, as displayed in Fig. 6b. The next-to-coal backfilling is a special form of the total-gob-in backfilling, where the wall neighbors the coal side of next mining panel, as illustrated in Fig. 6d. All of these potential positions may make sense under different geology and panel distribution, however, it is certainly that the backfilling wall concerns a lot as to overall stability of the entry. Original intact coal mass should turn into fractured coal mass as panel face moves closer, and the rotation of rock B is also irresistible. Hence, a relatively stable position should be revealed among these potential choices so as to

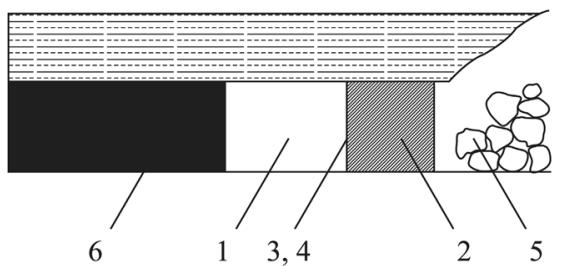

(a) Total -gob-in backfilling

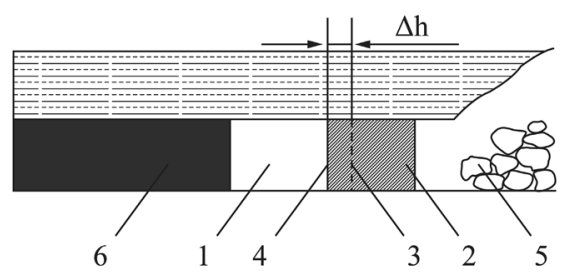

(b) Partial-road-in backfilling

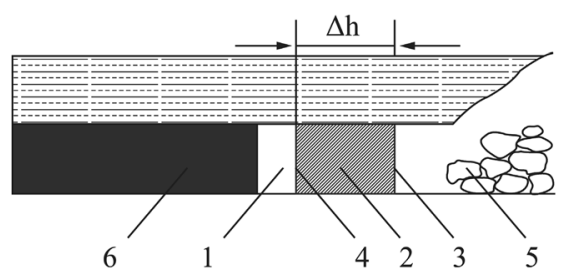

(c) Total-road-in backfilling

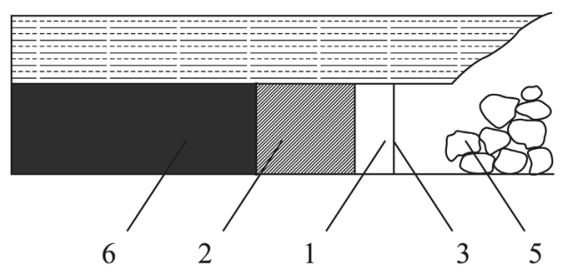

(d) Next-to-coal backfilling

1: Retained entry; 2: Backfilling wall: 2: Right edge of original entry 4: Coal-side edge of backfilling; 5: Gob area; 6: Coal seam

Fig. 6 Four arrangements between original entry and backfilling wall in original retained entry

accommodate the fierce and inconstant stress around the retained entry.

The position selection for backfilling wall is different from that for entry selection under the block B. The stress distribution of roof is correlated to the width of the entry, as indicated in Fig. 5, vertical force $F_{\mathrm{V}}$ is much more sensitive to the entry width $a$, these two factors show a positive relationship. Whereas it is much different from the torque $R_{\mathrm{m}}$, with its value showing no obvious vibration as 
$a$ increases. Hence, the influence of $F_{\mathrm{V}}$ is higher than that of $R_{\mathrm{m}}$ as to the correct position selection for backfilling wall. However, ventilation and transportation are two main functions of retained entry, thus it is impractical to take a relatively small value of entry width. On the basis of this consideration, partial-road-in backfilling is highly proposed to realize a compromising intention, and in order to obtain the exact value of $\Delta h$ in Fig. 6b, we conducted a field trial in Xieqiao Mine, as presented in the next section.

\section{Field trial}

Above conclusions certainly provide some important theoretical guidance for the field trial in this section. The position for field trial is located at face 12418 of Xieqiao Mine in Huainan Mining Group.

\subsection{Geology}

Face 12418 is a GER face, the coal seam is relatively simple and the overlying strata is a layer of mudstone with its thickness ranging from 0.1 to $0.4 \mathrm{~m}$. The gallery level for tailgate and headgate are -579.0 to 598.8 and -626.7 to $652.0 \mathrm{~m}$, respectively. The surface level is $18.3-27.1 \mathrm{~m}$, and the length of face is $212.8 \mathrm{~m}$. Lithological column for the face is shown in Fig. 7.

On the basis of our observation on periodic weighting and caving status at face ends, the fracture mechanism of the overlying lateral strata confirms to the model discussed in Fig. 2a. The entry is located under block B, and the position scope for the entry ranges from right below the

\begin{tabular}{|c|c|c|}
\hline \multicolumn{3}{|r|}{$1: 200$} \\
\hline Columnar & $\begin{array}{c}\text { Layer } \\
\text { thickness } \\
(\mathrm{m})\end{array}$ & Lithology description \\
\hline \begin{tabular}{|l|}
- \\
- \\
- \\
- \\
-
\end{tabular} & 5.18 & $\begin{array}{l}\text { Quartz sandstone, dark gray, locally contain } \\
\text { coal-bearing mudstone and little limonite, } \\
\text { stiff property } 4.22-6.14 \mathrm{~m}\end{array}$ \\
\hline \begin{tabular}{r|}
- \\
- \\
- \\
- \\
-
\end{tabular} & 2.80 & $\begin{array}{l}\text { Arenaceous mudstone, dark gray, the granules } \\
\text { stick together with each other and form into } \\
\text { clumps, it contains debris of white mica and } \\
\text { plantfossil } 0-4.57 \mathrm{~m}\end{array}$ \\
\hline 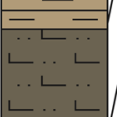 & 3.00 & $\begin{array}{l}\text { Coal No. } 8 \text {, black,oil and glass sheen, scaly } \\
\text { shapeand brittle, it belongs to semidurain and } \\
\text { semiclarain, the structure is simple, locally } \\
\text { contain mudstone } 2.6-3.3 \mathrm{~m}\end{array}$ \\
\hline$\div$ & 4.63 & $\begin{array}{l}\text { Mudstone, dark gray,the granules stick together } \\
\text { with each other and form into clumps, there } \\
\text { also has little debris of plant fossil.2.7-5.56 m }\end{array}$ \\
\hline & 0.88 & $\begin{array}{l}\text { Coal No.7-2, locally contain mudstone, } \\
0.4-1.37 \mathrm{~m}\end{array}$ \\
\hline- & 1.56 & $\begin{array}{l}\text { Mudstone, locally contain siltstone, } \\
0.79-2.71 \mathrm{~m}\end{array}$ \\
\hline
\end{tabular}

Fig. 7 Lithological column of face 12418
Table 2 Sizes for original entry and original retained entry (mm)

\begin{tabular}{llllll}
\hline \multirow{2}{*}{$\begin{array}{l}\text { Measure } \\
\text { sites }\end{array}$} & \multicolumn{2}{l}{ Original entry size } & & \multicolumn{2}{l}{ Original retained entry size } \\
\cline { 2 - 3 } & Width & Height & & Width & Height \\
\hline No. 1 & 3881 & 1640 & & 3135 & 2408 \\
No. 2 & 3590 & 1669 & & 2827 & 2335 \\
No. 3 & 3485 & 1625 & & 2861 & 2675 \\
No. 4 & 4776 & 2520 & & 3636 & 2864 \\
No. 5 & 4450 & 2980 & & 3911 & 2325 \\
\hline
\end{tabular}

hinge point of $A \& B$ to a third length of block $B$. Then five measuring sites are set in the retained entry for obtaining the appropriate position of backfilling wall, these five sites differ with each other in their original entry size and original retained entry size, as shown in Table 2 . It can be observed from the table that the proportions between the width of original retained entry and that of original entry are $80.8 \%, 78.7 \%, 82.1 \%, 76.1 \%$, and $87.9 \%$, respectively. Hence, all of these five measuring points belong to the partial-road-in backfilling way. Notice also that by analyzing the displacement law of higher coal side \& lower backfilling wall side and roof subsidence \& floor heave, it helps to present the best and the worst positions for the backfilling wall.

\subsection{Results and discussion}

\subsubsection{Monitoring results analysis}

(1) Deformation of higher coal side in different points As detailed in Fig. 8a, some similarities can be tracked in these five points. Obtained results indicate that deformation law of higher coal side in these five measure sites shows a high degree of consistency, the curves change is obviously not induced by the different size of original entry in Table 2, nor by the specific position of backfilling wall in retained entry in the same table. It appears from this evidence that the variation trend should be more related to overall mining-induced pressure. From another perspective, the upper area of higher coal side is close to the front part of block B, this situation is identical for all measure sites, thus the deformation of higher coal side is less related to the original entry size or original retained entry size. This should lead to a speculation that the variation of entry size is further related to some other factors like deformation of low backfilling side or displacement of roof/floor. Comparatively speaking, deformation of No. 2 site is the highest as the distance to the panel face is less than $63 \mathrm{~m}$, whereas it is No. 3 site who owns a leading position as the distance surpasses $63 \mathrm{~m}$, the peak 


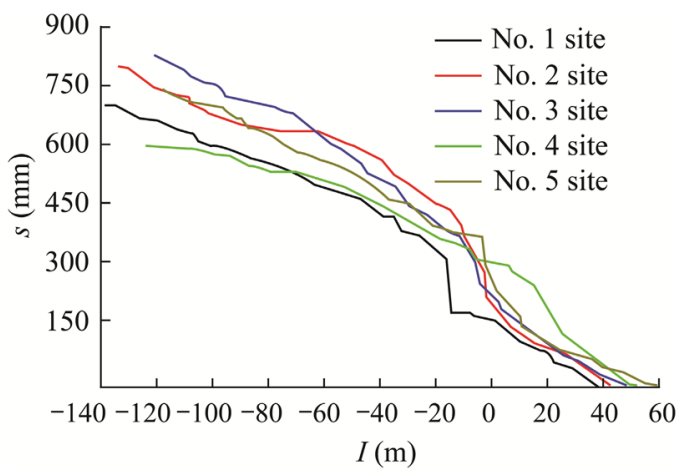

(a)

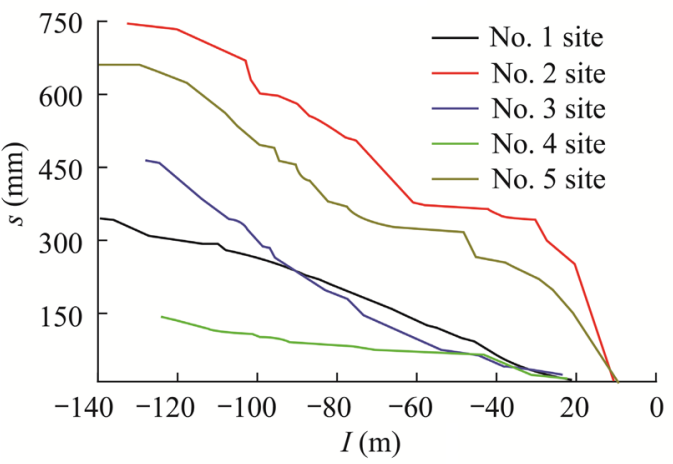

(b)

$I$ : distance from working face $s$ : deformation

Fig. 8 Comprehensive deformation from No. 1 to No. 5 sites

value of this site is $800.47 \mathrm{~mm}$, reached at $122 \mathrm{~m}$ behind the panel face. Additionally, the general minimum deformation is attributed to No. 1 and No. 4 sites, the critical distance for them is $71 \mathrm{~m}$, and the ultimate deformation for No. 4 site is the smallest one among these four sites, as indicated in Fig. 8a. On the whole, the largest deformation of the No. 4 site is $582.03 \mathrm{~mm}$, this value accounts for $72.7 \%$ of that of No. 3 site.

(2) Deformation of lower backfilling wall side in different sites

Figure $8 \mathrm{~b}$ displays the overall deformation of the lower backfilling wall side, it can be observed that all curves differ from each other. Consider their difference in original retained entry size, hence the curves divergence of the lower backfilling wall side is mainly induced by this kind of size difference, which also testifies the theory that the stability of backfilling wall can play a major role as to accommodate the subsidence, rotation, and deformation of roof.

Among these measure sites, deformation of No. 2 site is the largest and its peak value is $755.52 \mathrm{~mm}$. However, the overall mitigate deformation is

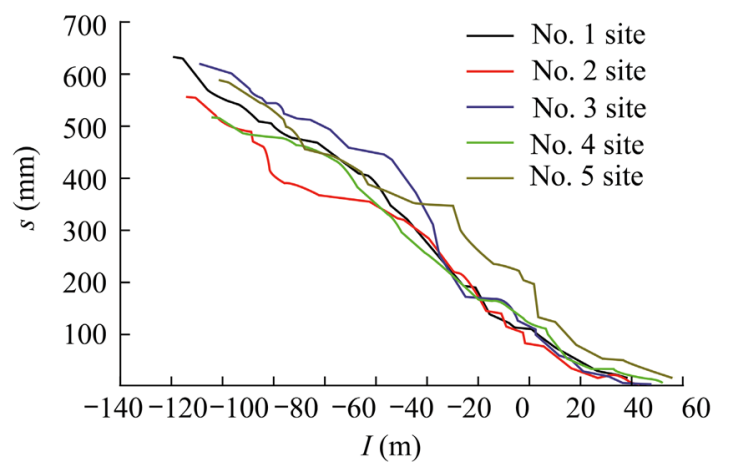

(a)

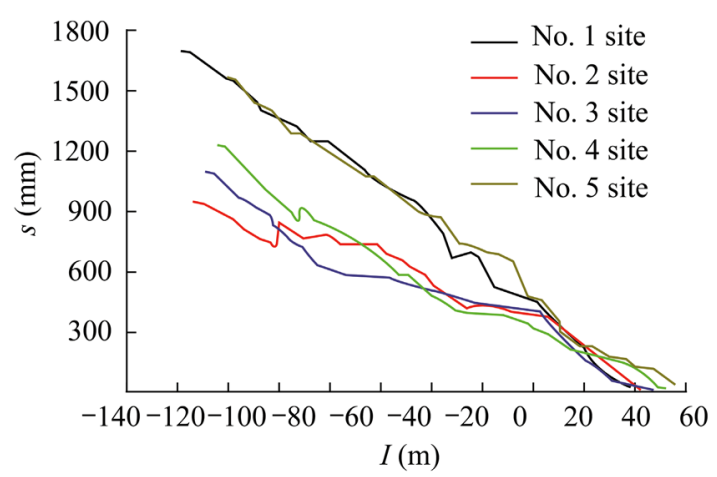

(b)

I: distance from working face $s$ : deformation

Fig. 9 Comprehensive deformation from No. 1 to No. 5 sites

reflected by No. 4 site, whose maximum deformation value is $133.92 \mathrm{~mm}$. This value only accounts $17.7 \%$ of that of No. 2 site, and it draws a conclusion that an appropriate width of retained entry can have a decisive position as to restrain the deformation of the lower backfilling wall side.

The curves of the rest sites are somewhere between the curves of No. 2 and No. 4 sites, Their descending order is No. 5 site, No. 1 site, and No. 3 site if their distance to rear side of panel face is less than $90 \mathrm{~m}$, whereas the order can changes into No. 5 site, No. 3 site, and No. 1 site if their distance to the rear side of panel face surpasses $90 \mathrm{~m}$.

(3) Roof subsidence in different sites

Monitoring curves of roof subsidence are displayed in Fig. 9a. All curves show similar changing trend. The maximum displacement is No. 1 site, which is valued by $643.53 \mathrm{~mm}$, whereas the minimum displacement is No. 4 site, which is valued by $518.36 \mathrm{~mm}$. Hence, it can be seen that the stability of roof is less concerned with the original retained entry size as compared with what indicated in Fig. 8 b, a possible explanation for this may lie in the fact that the position of lower backfilling wall is 
closer to the hinge point of block B and C, thus the wall will suffer a more severe stress disturbance. Additionally, roof subsidence of No. 1, No. 3, and No. 5 sites are relatively larger than that of No. 2 and No. 4 sites, and it is No. 3 site that has the overall largest subsidence at the rear side of panel face.

(4) Displacement of floor heave in different sites Displacement curves for floor heave can be seen in Fig. 9b. The scattered changing trend demonstrates that the original retained entry size has certain relationship with the displacement of floor heave. On the whole, the displacement recorded from this field trial has an strong concordance with the previous literatures that rotation and subsidence of block B can transfer fierce stress disturbance to the floor when the coal side under B is fully plastic. For example, at position where coordinate is $-136 \mathrm{~m}$, the floor heave in No. 1 site unexpectedly reaches $1694.82 \mathrm{~mm}$, This value is obvious not applicable for the normal ventilation and transportation of the entry in view of the original sizes of retained entry in Table 2. Hence, the appropriate position choice for backfilling wall should be given full consideration to avoid overlarge deformation.

Curves in Fig. 9b reveals that all of these sites share certain similarity, both of their displacement increases dramatically as the distance to the rear side of panel face rising. However, it is worth noted that the displacement of No. 1 and No. 5 sites are the largest ones, whereas the rest ones show no distinct difference from each other.

\subsubsection{Discussion}

Aforementioned analysis presents a conclusion that stress environment of No. 4 site is comprehensively mitigated if all factors are taken into consideration, and this site has a great superiority as compared with others. Among these sites, No. 5 is not an appropriate position choice because its deformation always leads the way in all sites. Besides, displacement of lower backfilling wall side in No. 2 site is much larger than No. 4 site, considering that the width of the original retained entry in No. 2 site is $2827 \mathrm{~mm}$ while that of No. 4 site is $3636 \mathrm{~mm}$, hence the optimal width for original retained entry is $3.6 \mathrm{~m}$ or so based on monitoring result of No. 4 site and Zhang's study (Zhang et al. 2001).

Moreover, it can be found in Fig. 9 that floor heave takes more than two-thirds of the roof-to-floor deformation in the whole section of retained entry. Hence the kernel of controlling the surrounding rock of GER is to acknowledge the appropriate time for dinting and reinforcement at

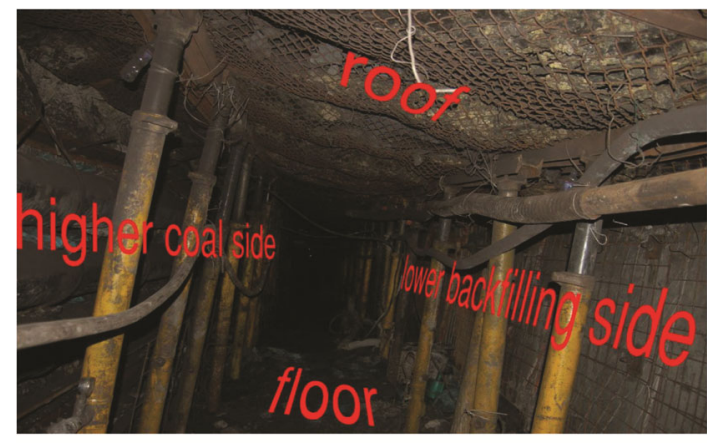

(a) $70 \mathrm{~m}$

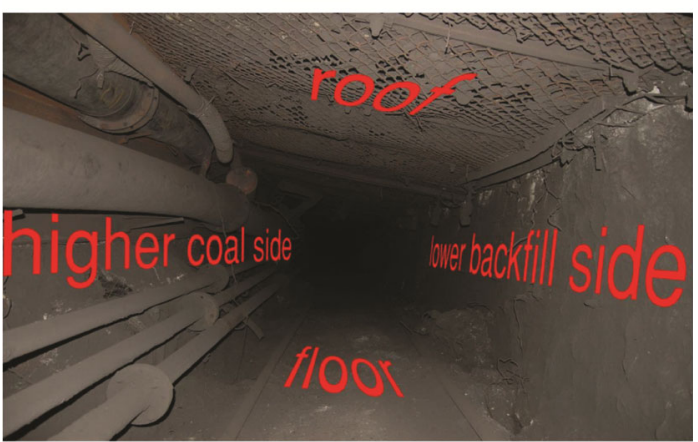

(b) $700 \mathrm{~m}$

Fig. 10 Field photos for GRE of face 12418 in Xieqiao Mine

retained entry segment. Some field photos for retained entry in Xieqiao Mine are attached as in Fig. 10.

\section{Conclusions}

(1) On the basis of the built model of blocks A, B, and $\mathrm{C}$, and different entry positions under block $\mathrm{B}$, this study obtains the vertical force and torque on the entry roof. It further demonstrates that vertical force can have an initial increase and a later decrease as the horizontal distance $\left(x_{0}\right)$ between the hinge point of blocks $A \& B$ and the higher coal side rises. However, the impact that the torque applies to the entry roof is much severer than what the vertical force does. The vertical force shows an overall increase as the width $(a)$ of the entry increases, but the torque is little influenced by the width $a$.

(2) In view of the similar geology like Huainan mining area, the optimal position for the entry under key block $\mathrm{B}$ is the position which closes to the hinge point of blocks $\mathrm{A} \& \mathrm{~B}$ and its appropriate range starts from this point to the one-third length of key block B along the horizontal direction, the stability of roof is much easier to be sustained if the entry position is in this range. 
(3) The engineering practice proves that a favorable way for backfilling is partial-road-in backfilling, which can bring a more stable stress environment for roof. The investigation also shows that deformation of higher coal side and roof is little influenced by the size of original retained entry, but the deformation of lower backfilling wall side and floor can be severely affected by the size.

(4) Results from engineering practice indicate that roof and two sides can be more stable as the size for the original retained entry is $3.6 \mathrm{~m}$ or so. Additionally, the width proportion between the original retained entry and original entry should avoid value choice $88 \%$ or so, which can cause drastic deformation fluctuations of surrounding rock/coal mass. The recommended value for this proportion should be around $75 \%$, the monitoring results testified that the deformation and stability under this circumstance can both meet the appropriate supporting cost and production needs.

Acknowledgments Financial support for this paper from the Program for Changjiang Scholars and Innovative Research Team in University (IRT_14R55), the Fundamental Research Funds for the Central Universities (NO. 2014XT01), and the Research Innovation Program for Graduate Students in Jiangsu Province (KYLX15_ 1400) are gratefully acknowledged. The participants of the engineering practice and the similar material simulation experiment are thanked for the data collected underground and the hard work they have done. In particular, comments and suggestions from $\mathrm{Na}$ Liu, Lei Zhang, Fei Xue and Jinbo Hua are practically valuable.

Open Access This article is distributed under the terms of the Creative Commons Attribution 4.0 International License (http://crea tivecommons.org/licenses/by/4.0/), which permits unrestricted use, distribution, and reproduction in any medium, provided you give appropriate credit to the original author(s) and the source, provide a link to the Creative Commons license, and indicate if changes were made.

\section{References}

Bai JB, Wang WJ, Hou CJ, Huang HF (2000) Control mechanism and support technique about gateway driven along goaf in fully mechanized top coal caving face. J China Coal Soc 25(5):478-481

Bai JB, Zhou HQ, Hou CJ, Tu XZ, Yue DZ (2004) Development of support technology beside roadway in goaf-side entry retaining for next sublevel. J China Univ Min Technol 33(2):183-186

Chen YG, Qian MG (1994) Surrounding rock control of Chinese coal mining stope. China University of Mining \& Technology Press, Xuzhou
Hou CJ, Ma NJ (1989) Stress in in-seam roadway sides and limit equilibrium zone. J China Coal Soc 14(4):21-29

Huang YL, Zhang JX, Zhang Q, Zan DF (2011) Technology of gobside entry retaining on its original position in fully-mechanized coalface with solid material backfilling. J China Coal Soc 10(36):1624-1628

Jiang JQ (1993) Surrounding rock stress and movement in stope. China Coal Industry Publishing House, Beijing

Kan JG, Zhang N, Li BY, Si GY (2011) Analysis of supporting resistance of backfilling wall for gob-side entry retaining under typical roof conditions. Rock Soil Mech 32(9):2778-2784

Li HM (2000) Control design of roof rocks for gob side entry. Chin J Rock Mech Eng 19(5):651-654

Ma LQ, Zhang DS (2004) Industrial test of road-in backfilling for gob-side entry retaining in fully-mechanized coalface with topcoal caving. J China Univ Min Technol 33(6):660-664

Qian MG, Shi PW, Xu JL (2010) Mine pressure and strata control. China University of Mining \& Technology Press, Xuzhou

Smart BGD, Davies DO (1982) Application of the rock-strata-title approach to the pack design in an arch-sharped roadway. Min Eng 144(9):91-178

Williams BC (1988) Backfilling technology. Min Eng 3:73-76

Xie WB (2004) Influence factors on stability of surrounding rocks of gob-side entry retaining in top-coal caving mining face. Chin $\mathrm{J}$ Rock Mech Eng 23(18):3059-3065

Xu YQ (2009) Coal mining, revised version. China University of Mining \& Technology Press, Xuzhou, China

Xue DP, Wang JP, Tu SH, Wang FT, Zhao J (2013) Deformation failure mechanism and application of the backfill along the goafside retained roadway. Int J Min Sci Technol 23(3):329-335

Yang JP, Cao SG, Li XH (2013) Failure laws of narrow pillar and asymmetric control technique of gob-side entry driving in island coal face. Int J Min Sci Technol 23(2):267-272

Zhang DS, Miao XX, Mao XB (2001) Simulation on roof activities of gob-side entry retaining in full-mechanized top-coal caving faces. J China Univ Min Technol 30(3):261-264

Zhang DS, Mao XB, Ma WD (2002) Testing study on deformation features of surrounding rocks of gob-side entry retaining in fullymechanized coal face with top-coal caving. Chin J Rock Mech Eng 21(3):331-334

Zhang DS, Ma LQ, Feng GM, Miao XX (2005) The technique of gobside entry retaining with entry-in packing on its original position in fully-mechanized coalface with top-coal caving. Chin J Rock Mech Eng 24(7):1164-1168

Zhang Y, Wan ZJ, Li FC, Zhou CB, Zhang B, Guo F, Zhu CT (2013) Stability of coal pillar in gob-side entry driving under unstable overlying strata and its coupling support control technique. Int J Min Sci Technol 23(2):193-199

Zhang N, Han CL, Kan JG, Zheng XG (2014) Theory and practice of surrounding rock control for pillarless gob-side entry retaining. J China Coal Soc 39(8):1635-1641

Zheng XG, Feng XW, Zhang N, Gong LY, Hua JB (2014) Serial decoupling of bolts in coal mine roadway supports. Arab J Geosci. doi:10.1007/s12517-014-1697-z

Zhu DR (1987) Fracture law and application of main roof in the longwall face. Dissertation, China University of Mining \& Technology, Xuzhou, China 